\title{
SEMIOTICS OF ENVIRONMENTAL GRAPHICS IN THE APPEARANCE OF THE PLACE IN URBAN ADVERTISING
}

\author{
Madari Mohades, Mahboubeh \\ Instructor And Academic Member, Department Of Graphic, Faculty Of \\ Art, Alzahra University,Tehran, Iran \\ www.alzahra.ac.ir
}

\begin{abstract}
Nowadays, all the cities of the word are replete with symbols, signs, and other educative and informational graphic elements considered to be the factor establishing order as well as assisting managers and executives in enforcing rules and regulations. Coupled with enacting the above-mentioned roles, they are also a tool for economic development. The prominent cities of the world compete with one another in terms of business and tourism; moreover, they are continually seeking more attractive and eloquent signs and procedures for guiding and attracting the visitors. Simultaneously, a plethora of buildings and centers are annually constructed all over the world, presenting more innovative and newer environmental graphic due to similar reasons. Service visual signs, traffic signs, visual and written guidance systems for private and public spaces, commercial advertisement, and dozens of other cases enact a highly significant as well as undeniable role in offering services, guiding, facilitating the traffic and urban transport, and informing. Environmental Graphic Designers can participate in properly organizing the environmental graphic elements along with architects, urbanists and other agents involved in design and construction of urban environments. Therefore, in the present study the attempt was made to investigate the role of environmental graphic in the beauty of the city and its impacts upon the advertising in the urban environment with a comprehensive approach.
\end{abstract}

Keywords: Environmental graphics, advertising, semiotics

\section{INTRODUCTION}

Advertising, nowadays, uses the Graphic art to fulfill its objectives. Graphics is necessarily a visual domain, having been used from ancient times with the aim of transferring visual beauty and concept. Beauty is the very inherent part of art. Here, the genuine concept of art is approached; from this perspective, the non-beautiful art is no longer something deemed to be an art. Ancient Iranians had possessed and subsequently used this art before the Achaemenid. Iranian carpet is one of the most beautiful graphics in the world. Its designers show the best taste in creating a beautiful work. The historical changes necessarily provided a condition that increased the necessity of informing in all areas including social, political, informational, religious, and commercial; hence, a field called "Modern Graphics" was emerged. Therefore, in today world, graphics may act not only as an art but as a media factor. The difference between advertising and graphics refers to the fact that advertising-based informing includes a sort of exaggeration. Advertising takes advantage of all means to achieve its commercial, political and social goals [4]. Indeed, literature, music, painting, and poetry are used in combination to transmit a message to the audience. In addition to their informational facet and their usability for the audience, graphical works are tantamount to the visual songs of a society. Graphical works are abundantly produced, however a limited number of works find their way to the art area. The aforementioned view is considered to be an artistic perspective (not merely a consumerist and profit-seeking view) [3]. Nowadays, due to the increased advertising companies, the number of designers is reducing. All over the world, designers are present in the places where ads are produced, and express the desires of advertising companies as images and graphics as well. The elements of environmental graphics are desired to be 
designed and created by following aesthetic and psychological aspects, so that they lead to tranquility, comfort, vitality, endurance, and resistance of man in industrial environments and mechanical life of the present era, in addition to possessing an appropriate quality in service provision and consumption [4].

\section{ENVIRONMENTAL GRAPHICS}

Nowadays, graphics is considered to be one of the prominent factors in advertising, informing, and disseminating of political, social and cultural knowledge; notably, in developed world, it is assumed to be one of the significant constituents of social life. Graphic design has a major role in promotional and commercial announcements of TV, cinema, packaging, traffic signs, shop windows and street decorations, public places including hotels, airports and subways, restaurants and parks, shops, different artistic, cultural, and sport places, writings and advertisings on buildings and vehicles such as buses, trains and planes, and billboards and large-scale graphics, murals, pictograms and symbolic signs. Environmental graphics as a branch of graphics has a significant role in meeting the above-mentioned objectives, and constitutes a main part of advertising-related and commercial activities [10].

Our surrounding environment, the home where we live, the street where we traverse, the green space where we walk, the park where we go for entertainment, all require a logical formic relationships as well as precisely organized relations based on principles of visual expression. Man may talk to the surrounding environment and communicate others through environmental graphics. Environmental graphics has an effective role in establishing a favorable environment for the members of the society [4]. An appropriate environment simply means an environment in which man can grow and flourish free from unwanted mental pressure. The aforementioned condition is deemed to be the logical and rational desire of any nation. Environmental graphics is visual beauty and desirable order and harmony of the space. All graphic designs for interior and exterior environment are tended to create a space for lively, healthy, and satisfactory living. Environmental graphics can be divided into two types, namely two-dimensional or flat, and three-dimensional or volumetric. Distinguishing a place from another; beautifying, organizing, and systematizing the urban spaces; and expanding the activity scope of graphic art are considered to be the objectives of environmental graphics [9].

\section{THE PURPOSE OF ENVIRONMENTAL GRAPHICS}

1. Guiding people with the simplest way

2. Beautifying performed through using the principles of form and design, and their harmonization with each other and with their surrounding environment.

3. Increasing the cultural level in the society as the form of cultural and commercial advertising objectives through murals, banners, etc.

Environmental graphics aims at harmonizing its designs and whatever had existed before that in the environment. Determinant factors including the geography of the environment, weather, sunlight, rainfall, thermal fluctuation, vegetation, and so forth as the natural parts, and a series of factors such as the type of architecture and materials, traffic spaces, the traffic level, and so forth as the constructed parts resulted from the presence of man are factors required to be identified and taken into account by the designer during the working process [6].

\section{THE APPLIED AREAS OF ENVIRONMENTAL GRAPHICS}

- Familiarity with the culture of the society and recognition of its norms, values, customs and regulations have the utmost significant in Environmental Graphic Design (EGD).

- When the designer is profoundly familiar with the culture and morale of members of the society, $\mathrm{s} /$ he could easily and straightforwardly establish a simple and deep relation with the audience [5]. Environmental graphic is a science in which the way of using different types of forms, colors, motifs, and 
images in a planned, skilful, and principal manner are presented and investigated to improve and simplify the relations, informing and tracking, and also to create the beauty of public environment. On this ground, the applied scope of environmental graphics is highly expanded.

- $\quad$ Signs, symbols, and motifs assigned to public places, e.g. airports, hospitals, etc.

- $\quad$ Traffic signs

- Informational boards about the time of arrival and departure of trains and planes, route guidance boards for travelers, place for get on and get off, etc.

- Graphic designs and advertising on the stores entrance portals, buildings symbol, and writings on the tracks and other vehicles constitute writings mainly combined with specific signs.

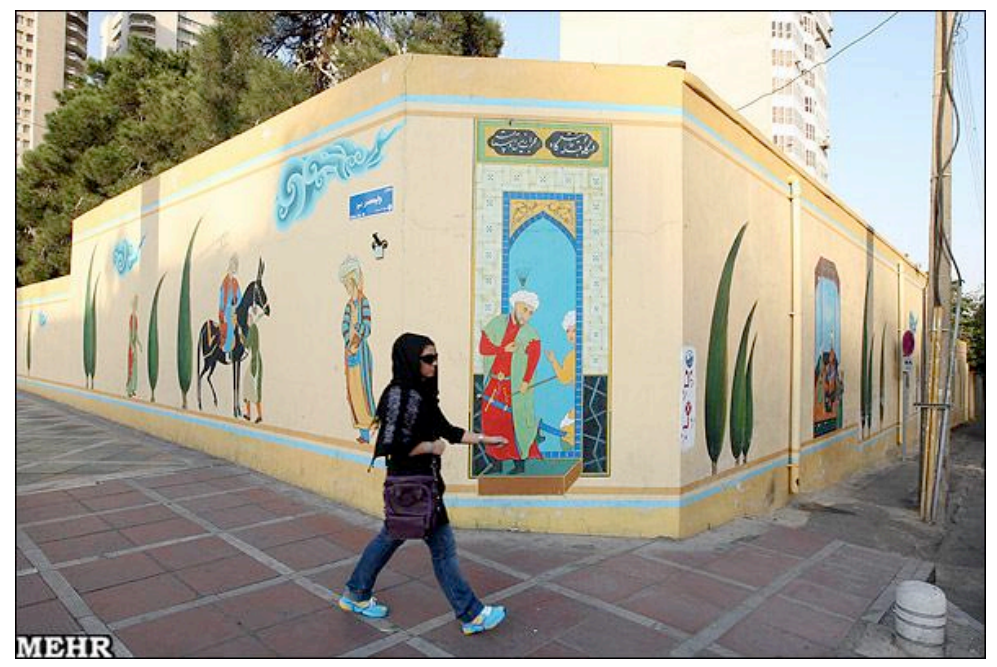

Figure 1: murals (creating attractive spaces in urban environment)

\section{ENVIRONMENTAL GRAPHIC AND ITS IMPACT UPON THE SOCIETY}

When a graphic design is directly in contact with different strata of the society and it aims at creating a desirable and pleasant atmosphere in line with the age, culture, and the morale of that community, it is considered as environmental graphics. Needless to say, if the required arrangements fail to be applied on behalf of handlers in different areas for appropriate and principal designing of components of environmental graphics, the biological environment and the lives of citizens may be spatially unaffordable and full of tension. Indeed, creating a proportional set -from the perspective of color and form- may pave the way for the hopefulness and attraction of people of the society towards life, provide public enthusiasm, and endow the society with new spirit. Color has a substantial role in environmental graphics, for it creates façade. For instance, a red double-decker bus may remind us of London, hence colors like red and its complementary colors may be stimulating in this city or northern cities with a wide green spaces. Therefore, environmental coloring is required to be in line with climate considerations, for instance for people living in tropical environment, warm colors have to be avoided, instead cool colors are recommended to be used, like turquoise and blue domes in the ancient desert textures [8].

\section{AESTHETICS IN URBAN GRAPHICS}

Considering the principles of aesthetics in urban graphics as one of the indicators of urbanization and culture-establishing process is a matter of great importance [5]. Given the history of graphics, the first signs of graphics trace back to the times before the invention of script. After that period, along with the invention of script and diversification of languages and dialects, the need for a common visual language was felt, and then graphics (as a means to simplify the message) gradually found its way to the art world as a new branch of art [3]. On the function and purpose of graphics for the audience, rapid, clear, and error-free transmission of message to the audience deserves mentioning. Therefore, it has found a special 
status in a number of areas, e.g. advertising and different media in urban environment. Regarding the aesthetics in urban graphics, architecture and aesthetics factors enact an essential role; accordingly, considering a fundamental infrastructure with the presence of skillful persons is assumed to be a matter of special importance before designing any graphic action. In addition to a graphic artist, the presence of an aesthetics expert is deemed to be essential in urban advertising; however, we face the lack of the aforementioned field of study in universities [2]. Comparing the methods of urban graphics from the past up to the present may reveal that in the past -the period after the Imposed War (Iran-Iraq) - due to the absence of billboards, worn-out walls and poor facilities were available for urban graphics, which were both highly expensive and low quality. On the contrary, nowadays, billboards are used for different ads. Modern graphics of the present era was made by taking advantage of experiences of other nations; however, they have to be adapted to the culture and social origins of our country. Besides, choosing an apt location for the more effectiveness of the message on the audience seems to be a fundamental point.

The essential role of urban graphics in urbanization indicators having a special as well as substantial impact on the outcomes such as tranquility of the members of the society, traffic control, and culture establishing. Considering the points outlined above and using new strategies by the assistance on behalf of authorities seem to be helpful [9].

\section{URBAN ADVERTISING}

Urban advertising as a branch of environmental graphics has a significant role in promoting the culture and economy of a nation. Our contemporary world is rapidly moving forwards, and technology is the main stimulus of such a pace. Technology leads the life of man towards construction, production, and variation in the two former; therefore, a supply and demand market may be required, and advertising is assumed to be the most important tool in meeting such relations. Urban advertising as a subset of environmental graphics is responsible for transmitting messages. Educational, cultural, social, economic, commercial, and political messages may be easily exposed to public eye by urban advertising; moreover, the latter may guild people into how to live a better life [6].

\section{Types of spatial locations for urban advertising}

Choosing an appropriate place for environmental advertising is considered to be one of the important and fundamental factors, and it may have a dramatic effect on the audience provided that it is properly chosen. The best places for the above-mentioned purposes are presented as follows:

Intercity spaces

- Intercity highways

- $\quad$ Toll road

- $\quad$ Road policing

Public transport terminals

- Urban bus station

- Intercity passenger terminals

- Urban Train

- $\quad$ Airport

- Railway

Fueling stations:

- Gas station

Submit Date: 01.05.2016, Acceptance Date: 24.06.2016, DOI NO: 10.7456/1060JSE/048 Copyright (C) The Turkish Online Journal of Design, Art and Communication 
CNG fueling station

Public centers:

- Tourist recreational complex

- $\quad$ Shopping center

- International Exhibition

- $\quad$ Sports' fields

Spatial locations:

\begin{tabular}{ll} 
- & Streets \\
- & Squares \\
- & Pedestrian bridges \\
- & Roadway overpasses \\
\hline
\end{tabular}

Different aspects of environmental graphics

- Informational aspect (i.e. emphasis on or warn about a specific subject)

- $\quad$ Cultural aspect (e.g. urban advertising about theatre, movie, etc.)

- $\quad$ Educational aspect

- $\quad$ Social aspect (e.g. advertising against smoking in the city)

- $\quad$ Aesthetic and artistic aspect (merely beautification)

Balance, proportion, emphasis, continuity, unity and variation are the principals of a proper organization. Color, light, form, line, point, surface (plane), texture, and space help the above-mentioned factors to create a desirable as well as beautiful work.

\section{Balance}

Balance is one of the fundamental principles of art. Art may seek a sort of balance in communicating with the audience. Balance is resulted from the balanced division of components. Color, light, and texture may have role in balance or imbalance. However, the more emphasis on balance may lead the work to lose its attraction and create lackluster.

\section{Proportion}

Meeting proportion (proportionality) is another basic principle of art. A point that should be taken into account in designing the entrance portals of a store is that in cases there is a broader site or there is blank spaces around the respective store or public place, designer has more options and could change the ordinary proportionalities. For instance, the designer could consider the portals of the respective store or public place taller than usual, for due to the wideness of the respective environment, the viewer is completely dominant on the environment and could easily see the portals and recognize it as well.

\section{Continuity in the environment}

Repetition, progression, and proportion are three basic principles of continuity in art. Proportion which is done by alternatively (every other or more) repeating different units has more complexity and movement. The effectiveness of repetition and alternation depends on the appropriateness of the subject matter and dexterity used in applying them, so that a gradual change in the order of repetition of an element may lead to the increased (progression) weight of the work as a whole. Progression could be directed either upward or downward or sideward. Progression could be observed in size change (small or large), shape change (from quadrangle to circle, etc.), and color change (from light to dark). 


\section{Emphasis}

When by reducing the importance of the components of a composition and distinguishing one of the components from others, the focus of the viewer is attracted towards a specific part of the work, the latter is named the emphasis point. The emphasis can be created by color, light, and texture. Similar components may weaken the emphasis point. The clear and transparent shapes and weird shapes have more ostentation than, respectively, ambiguous and simple shapes. The categorization of components also add the emphasis of a set. The principle of emphasis can be used either for unity or for variation. Emphasis on an element has a direct impact on the attraction of audience or visitor of a public place.

\section{Establishing unity in an environment}

Unity may endow each work with a sort of consistency. Without the element of unity, the components of a composition may seem scattered and irrelevant. Unity may lead to attraction; it is also a significant factor in transmitting the message by making the latter more comprehensible and helping it to become more simplified.

\section{Variation in the environment}

Variation is the product of difference and contradiction. Difference between the shape, color, and the texture of the constituent elements is named variation. Different components may enforce eyes into seeking the element of unity in the whole work. Variation, in fact, consolidates the unity. The latter tends to order; however, the former tends towards stimulus.

Point, line, and surface (plane) have special power of expression. The points are different due to the size and way of being applied in the environment and create a visual impact. Lines, e.g. curved lines, broken lines, diagonal lines, and lines in horizontal or vertical position, also have different dimensional impact. The above-mentioned lines are used as required and in well proportionality with the work.

The space is the determinant factor of location and state of each objective (concrete) phenomenon compared to the others. Space determines the existence of each objective creature in relation with the other creatures, and makes the interior, exterior and central spaces more comprehensible

\section{Texture}

Texture can be discussed from two facets, i.e. form and shape, and physical property and type of texture. The former is understood by the sense of sight, the latter but with the sense of touch.

The degree of reflection or absorption of light by the object's texture is important. The contrast of opaque and rough surface as juxtapose with the bright and shiny surface may lead to more attraction and establish visual effect as well. Rough textures have a high power of attraction; on the contrary, smooth and polished textures are frequently paled and unattractive. Texture is resulted from different materials including the bark of tree, stone surface, animal skins or artificial types such as brick, metal, plastic and so forth. Naturalness or artificiality of texture may affect its quality. Moreover, the point of view and the distance of the observer of the work also have to be taken into account.

\section{Light}

Light is one of the most important components in environmental graphics and interior and exterior design. Natural and artificial lights have diverse impact on the environment. The vantage point, the amount of light shining on the work, and the viewing angle of the viewer are the factors required to be observed in all interior elements of the street, beautifully and appropriately fit together, and follow a good and standard design. 


\section{CREATIVITY IN ENVIRONMENTAL ADVERTISING}

In a market replete with various products and services, creativity says the first word, whether in production or in advertising. If advertising for marketing fails to be creative, it will be boring and tedious for the audience, then the advertising producers are deemed to perform a futile work. Advertising may have a desirable impact if it is somewhat unique, that is to say, your advertising is foregrounded compared to others. A further point is that uniqueness has to be in line with the brand identity; otherwise, it will miss its audience [4]. Stephan Vogel is the Chief Creative Director at Ogilvy \& Mather office. As an avant-garde in the area of creativity, he observes: "Nothing is more efficient than creative advertising. Creative advertising is more memorable, longer lasting, works with less media spending, and builds a fan community...faster."

A creative work is thoroughly formed based on what has been previously built. A novel idea is a combination or integration of one or more previous ideas. No matter how such an idea comes to our mind, the matter of importance is the way of applying and updating it. Hence, familiarity with creative strategies and techniques as well as better and deeper understanding of their mechanism and their way of working may lead to the development of mental spaces and discovery of new ideas [1].

\section{THE ROLE OF ENVIRONMENTAL GRAPHICS IN ENVIRONMENTAL ADVERTISING}

Environmental graphics as a branch of graphics has a considerable role in achieving the above-mentioned objectives. It also covers a main part of commercial and advertising activities. Our surrounding environment, the home where we live, the street where we traverse, the green space where we walk, the park where we go for entertainment, all require a logical formic relationships as well as precisely organized relations based on principles of visual expression. Environment advertising as a branch of environmental graphics has a significant role in promoting the culture and economy of a nation. Our contemporary world is rapidly moving forwards, and technology is the main stimulus of such a pace. Technology leads the life of man towards construction and production and variation in them; therefore, a supply and demand market may be required, and advertising is assumed to be the most important tool in meeting such relations. Environmental advertising as a subset of environmental graphics is responsible for transmitting messages. Educational, cultural, social, economic, commercial, and political messages may be easily exposed to public eye by urban advertising; moreover, the latter may guild people into how to live a better life [7].

Environmental advertising including large advertising boards (billboards), wall panels, aluminum boards (tetrahedral and triangular advertising station), three-dimensional rotating boards, six-sided boards, digital signboards and banners, campaign posters in bus stations and subway, poster transit (advertising inside buses), and wall panels as the advertising of external environment and environmental graphics of the city can well enact advertising role in the city.

In a comprehensive and overall summary, the main applications of environmental graphics and its area of activity can be categorized as follows [7]:

- Visual signs of urban public services

- Traffic signs in cities and highways

- $\quad$ Guiding visual and written signs in public and private places

- $\quad$ Commercial and advertising posters and ads

- $\quad$ Beautification of public places and thoroughfares

- $\quad$ Symbols and entrance portal of centers and public/private places

- Educational, cultural, commercial, and informational advertising boards (e.g. flat panels, billboards, revolving signboard, multi-faceted boards, digital signs and banners, wall panels and ...)

- $\quad$ coloring and arrangement of decorative elements of buildings and urban places

Submit Date: 01.05.2016, Acceptance Date: 24.06.2016, DOI NO: 10.7456/1060JSE/048 Copyright (C) The Turkish Online Journal of Design, Art and Communication 
- designing of kiosks and showcases of shops and exhibitions, and partitioning (separating) the spaces of administrative, commercial, and service centers

- $\quad$ Graphic design and coloring of motifs on the walls, bridges and vehicles

- $\quad$ Decorative elements of urban spaces

- $\quad$ Environmental Graphics of green spaces, parks and walkways

- Environmental Graphic of urban furniture (e.g. stations, parks, entertainment centers, offices, hospitals, schools, universities and ...)

- $\quad$ Beautification of squares and passages (fountains, decorative volumes, etc.)

- Designing of environmental decorations for ceremonies (e.g. festivals, competitions, feasts, holidays, religious rituals, etc.)

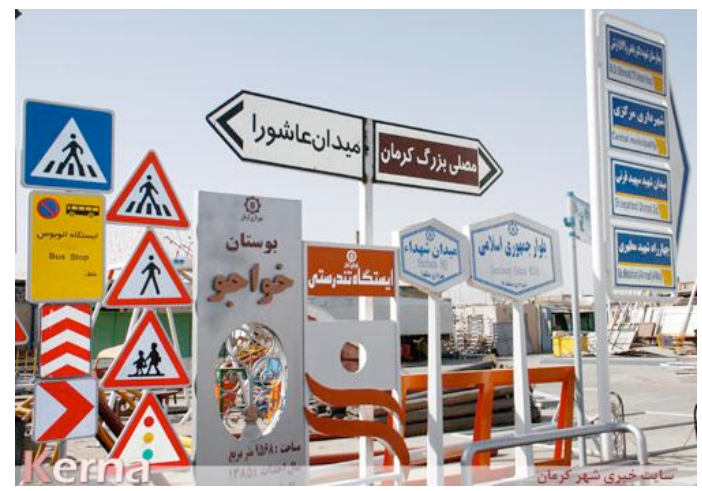

Figure 2: urban guiding visual-written boards

\section{URBAN LIFE AND ADVERTISING}

Now, it is evidently observed that by considering commercial needs and their plans, most advertising companies in their plans and investigations mainly emphasize on the importance of effectiveness and usage of historical texture and interaction between people and cities. In fact, they believe that advertising is the language of cities, which can be mostly taken advantage by using the knowledge of business. Therefore, the relation between advertising and the history of the cities can play a key role, exactly the same as the role of advertising in the streets of London and Times Square of New York. The matter of fact is that, advertising can change the habit of living in cities in different ways. For instance, when each day starts with a specific advertising, the latter may find its way in the lives of people and turn into the main part of urban life in Europe and American cities over time. Then, there is overwhelming evidence corroborating the notion that advertising constitutes a part of all generations and paves the way for accepting new ideas about life. Observing popular brands in the margins of the cities, even the unfamiliar cities, makes them to seem no longer strange, even if no one so far has traveled to the respective city. Ads can provide a condition for a traveler to feel at ease as though the unfamiliar city is his/her own home. Such a sort of advertising not only portrays brands, logos, and words, but also vivifies a symbol of culture in public minds. When macro environmental advertising is tackled, no matter to what issue the advertising is dealt. The respective advertising has to be resulted from the culture and the society itself [10]. Compatibility with culture simply means that the designer has to well know the culture, literature, and tradition, even the daily words used in daily communications of people have to be taken into consideration. Therefore, when a motto is about to be designed for a commercial product, it has to be thoroughly in line with the most fundamental properties of tradition and culture of that people. Knowing 
the culture of a society is a matter of great importance. A graphic artist has to be totally aware of his/her society. The matter of truth is that, when the relation of a designer with the society is ceased, his/her design is no longer alive. Therefore, a graphic artist and his/her design is dead, unless the designer is permanently exposed to different media and relatively aware of different issues to be able to offer his/her message to the society. What is more, a society will be shattered if the mere tradition dominates the advertising of a society.

\section{THE ROLE OF BILLBOARDS IN BEAUTIFICATION OF URBAN SPACE}

Meanwhile, billboard has a crucial role in beautification of the face of the city.

In $19^{\text {th }}$ century AD, advertising was mainly relied on printed posters; however, with the development of technology, billboards could change the face of the city. Nowadays, billboards are mostly known as extremely large boards with special lighting installed on tall bases visible from long distances [5]. As viewers, we are free to have different views about the advertising billboards; however, there is no escaping the fact that billboards are the symbol of permanent and flowing stream of life. In most countries, such an advertising may help people to find a place for eating, sleeping or fueling, particularly a country like America with numerous inter-city highways, long distances, and uninhabited places. The presence of such boards may be a blessing for foreigners and tired passengers. Moreover, these boards may help most companies and industry owners to introduce their new business to the people. Indeed, billboard is one of the attractive environmental media, constituting a part of identity of large cities and is considered to be a part of urban symbol like telephone booths and bus station.

Billboard conceptually refers to: "transmitting the highest amount of messages with the least words during the shortest time through an allocated environmental space". In the historical European countries, by installing these large boards in the external spaces of the cities, the attempt has been made to portray a part of the history of region in question; however, the commercial facet is also taken into account, hence in this condition the importance of graphics is more than past.

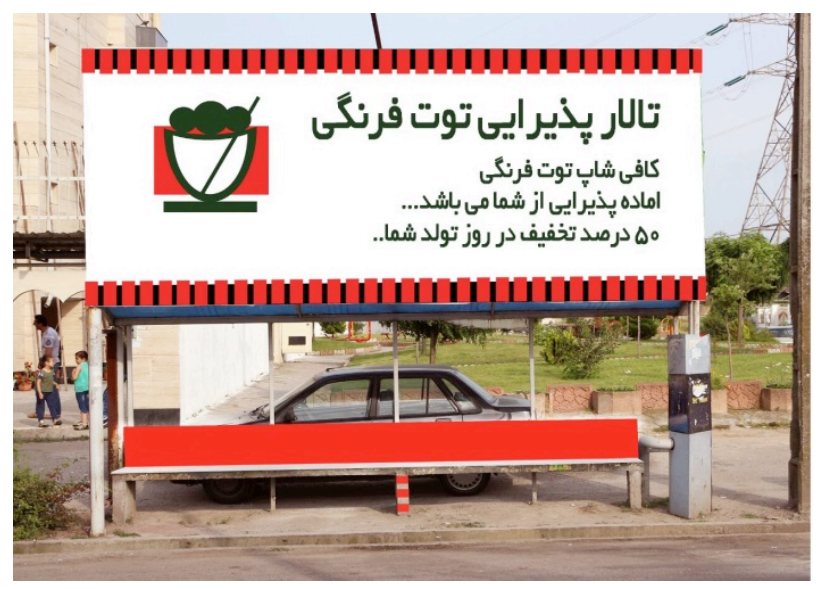

Figure 3: The role of billboards in beautification of urban space

\section{THE ROLE OF ENVIRONMENTAL GRAPHICS IN ADVERTISING}

Nowadays, graphics is known as one of the most prominent factors in advertising, informing, and disseminating of political, social and cultural knowledge; notably, in developed world, it is one of the 
significant constituents of social life. Graphic designs in commercial boards, even in TV ads, have an important role. Some analysts believe that graphics used in traffic signs, shop windows and street decorations, and even public places including hotels, airports and subways, restaurants and parks, shops and sports, different sport, artistic, and cultural places; writings and even advertisings on buildings and vehicles such as buses and planes undoubtedly affect the urban life.

Environmental graphics as a branch of graphics has a considerable role in achieving the above-mentioned objectives. It also covers a main part of commercial and advertising activities. Our surrounding environment, the home where we live, the street where we traverse, the green space where we walk, the park where we go for entertainment, all require an appropriate logical visual relationship. For man talks to the surrounding environment and interacts with others by means of environmental graphics [10]. In fact, environmental graphics is the common border of the art of architecture and graphics art, involving even the installation of a statue across the city and murals in the cities. Using architectural letters on the body of buildings are another forms of environmental graphics. In the middle of all these, Super Graphics including posters and billboards are the main elements of such a sort of graphics, for the application of artistic values are observed on the billboards in the frame of commercial ads. Designers could allude to some cultural points (establishing desirable culture) through commercial works and packaging, they also could affect people by using appropriate color and form. Good ideas in designing may enforce the viewer into thinking, therefore, consumption and purchase of the product are not the purpose of advertising. Nevertheless, the aim is to transmit a sort of information in terms of correct way of using and honesty in the quality of the product to the consumer. The above-mentioned purpose is achieved through a combination of writing and image [2].

Suitable composition of writing and image in an advertising may target the taste of the observer. Advertising has to indirectly transmit the information and awareness to the viewer; moreover, good and correct way of living may be involved in a commercial advertising.

Nowadays, advertising messages in countries are tending towards the provision of social benefits. The idea of green space, Earth crisis, and nature destruction are addressed in the advertising. Such a sort of advertising fails to target the purchase of the product but the better way of living. Finally, more supreme objectives are pursued and commercial competition is not the mere issue taken into account.

\section{FACTORS INFLUENCING ENVIRONMENTAL GRAPHICS DESIGNING VARIATION IN THE ENVIRONMENT}

Variation is the product of difference and contradiction. Difference between the shape, color, and the texture of constituent elements is considered variation. Different components may enforce eyes into seeking the element of unity in the whole work.

Variation, in fact, consolidates the unity. The latter tends to order; however, the former tends towards stimulus. 


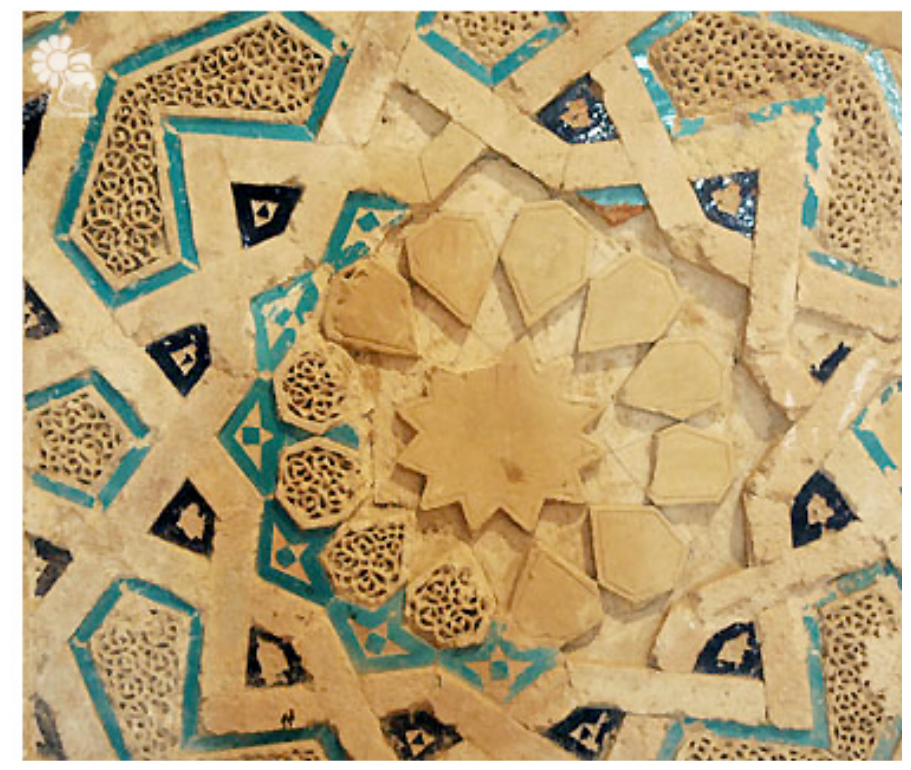

Figure 4: the variation of shape, color and texture

Point, line, and surface (plane) have special power of expression. The points are different due to the size and way of being applied in the environment and create a different visual impact.

Lines also, e.g. curved lines, broken lines, diagonal lines, and lines in horizontal or vertical position, also have different dimensional impact. The above-mentioned lines are used as required and in well proportionality with the work. The space is the determinant factor of location and state of each objective (concrete) phenomenon compared to the others. Space determines the existence of each objective creature in relation with the other creatures, and makes the interior, exterior and central spaces more comprehensible

\section{TEXTURE}

Texture is another environmental graphics element that can be discussed from two facets, i.e. form and shape and physical property and type of texture. The former is understood by the sense of sight, the latter but with the sense of touch.

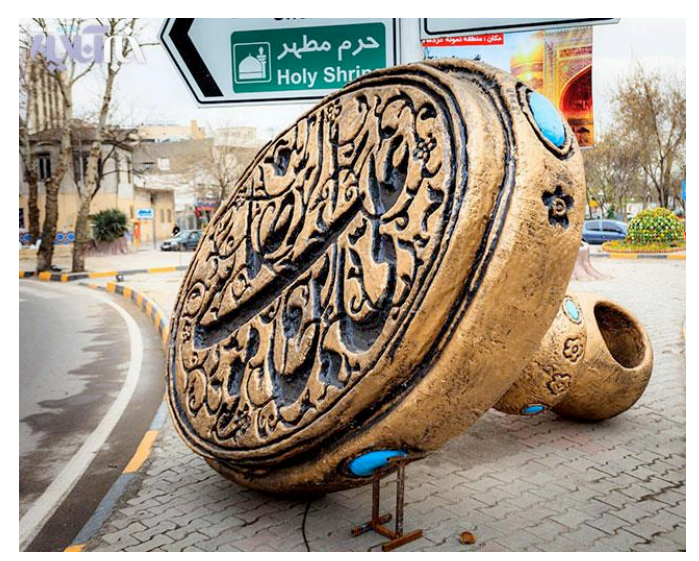

Figure 5: texture in environmental graphics 
The degree of reflection or absorption of light by the object's texture is important. The contrast of opaque and rough surface as juxtapose with the bright and shiny surface may lead to more attraction and establish visual effect as well. Rough textures have a high power of attraction; on the contrary, smooth and polished textures are frequently paled and unattractive. Texture is resulted from different materials including the bark of tree, stone surface, animal skins or artificial types such as brick, metal, plastic and so forth. Naturalness or artificiality of texture may affect its quality. Moreover, the point of view and the distance of viewer of the work also have to be taken into account.

\section{Light}

Light is one of the most important components in environmental graphics and interior and exterior design. Natural and artificial lights have diverse impact on the environment.

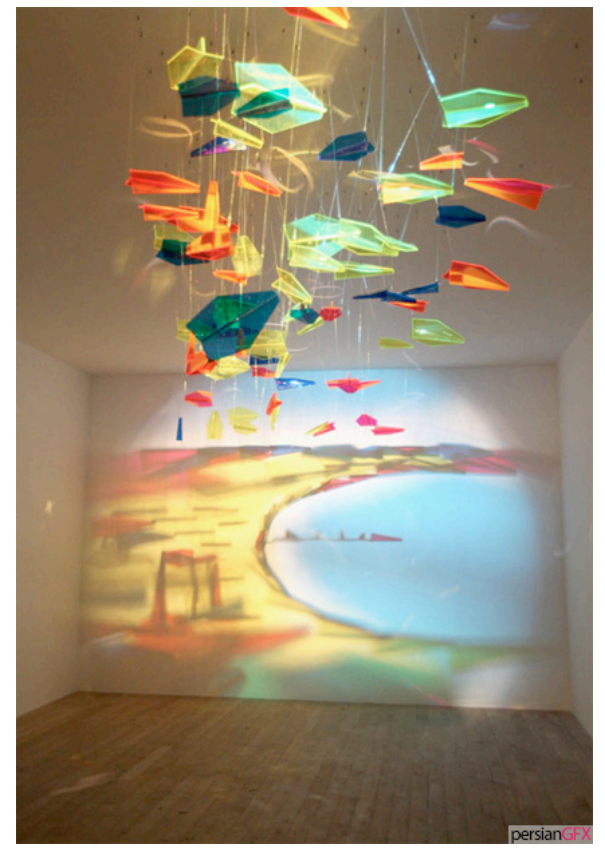

Figure 6: the effect of artificial light in environmental graphics

The vantage point, the amount of light shining on the work, and the viewing angle of the viewer are the factors required to be observed in all interior elements of the street, beautifully and appropriately fit together, and follow a good and standard design. Traffic signs, lighting fixtures, mailbox, trash buckets, street's name plaques, public telephone, murals, posters, bus stations, the stores entrance portals all are in relation and extremely affect the public opinion, hence they have to be pleasant as well as beautiful and help the beautification of the city by observing the aesthetic principles and appropriate composition. The fact of the matter is that, urban environment requires such a visual beauties to reduce the negative mental impact of the civilians. Environmental graphics makes the space and the environment more beautiful and more vivacious and endows the urban environment with a special order [6].

\section{ENVIRONMENTAL GRAPHICS AND ITS IMPACT ON DAILY LIFE}

The relations of present era have different forms from satellites to wrist watch; however, the modern sciences have failed to replace the traditional forms of communication such as writings, signs, etc. 
By the way, regarding the fact that the society is rapidly moving to complexity, the signs are also developing, so that the presence of numerous signs has created a sort of visual pollution; therefore, nowadays the attempt is made to escape visual disturbances [1]. Environmental graphics design is neither a mere art nor a mere science, but an amalgam of the former and the latter. Designing has to be a combination of effective creative impacts as logical examination, technique and the way of doing work. The result of such a combination are the signs effectively communicating people. In environmental graphics, the attempt is made to provide an appropriate condition for the living of contemporary man by relying on and using artistic creative experiences. In environmental graphics, the link of man to the environment is modified, the unnecessary and inaccurate points are removed, and the essential points are emphasized and foregrounded. In environmental graphics, informing, simplification, and comprehensibility of man communications and new and appropriate aesthetics are taken into account [2].

Some of the areas of Environmental Graphic [9].

- $\quad$ Outdoor graphics

a. Façade (materials, color, dimensions, design, etc.)

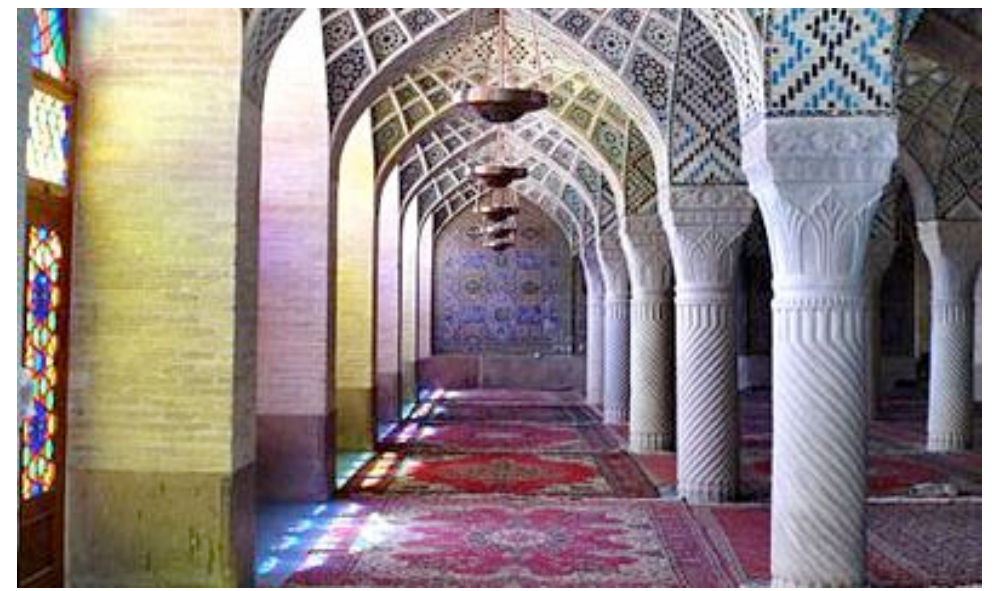

Figure 7: motif and color in architecture

b. booths (bus station, ticket, telephone, newspaper, police) 


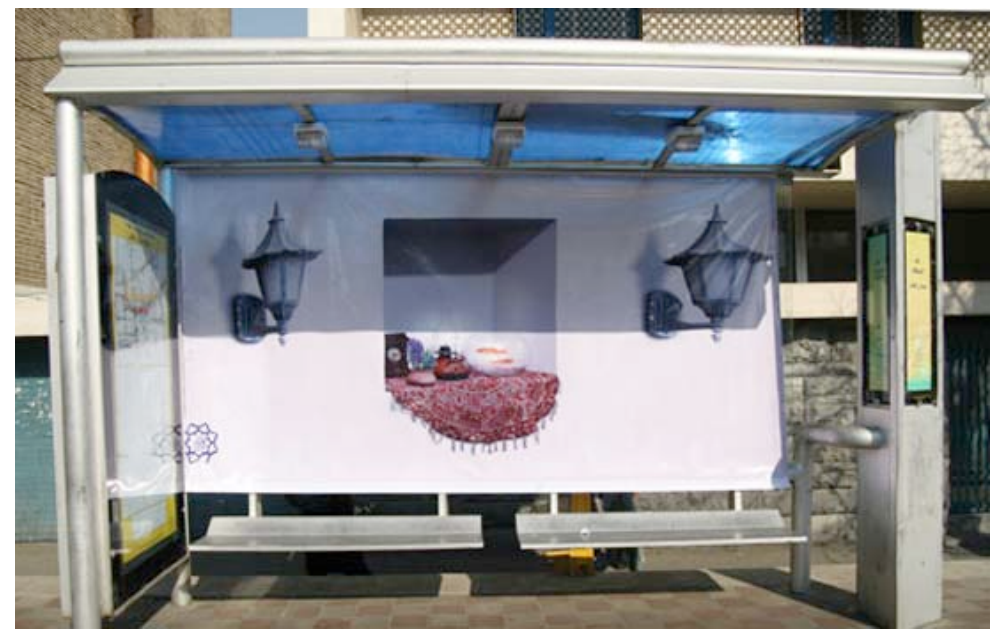

Figure 8: a view of a bus station with graphic design

c. waterscapes

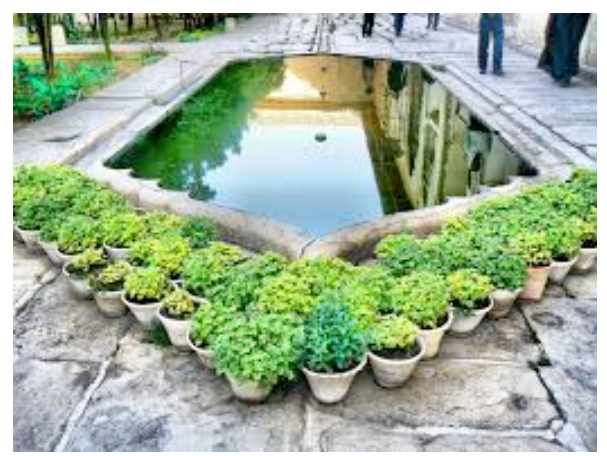

Figure 9: picture of a waterscape outdoors

. Graphic volumes

e. Light playing

f. advertising (murals, banners, vehicles, etc.)

- $\quad$ Indoor environmental graphics

In indoor environmental graphics, the informing can be separately done. Generally, its classifications can be summarily presented as follows:
a. Showcases
b. Booths and exhibition spaces
c. Domestic spaces

Environmental graphics is a science in which the way of using different motifs, images, forms, and colors are proposed and tackled in a skillful, principal and planned way to make the relations, communications, and traffic better and simpler and also to make the public place more complete [5]. 


\section{CONCLUSION}

Studying valid resources, and observing the proper basics and principles of environmental graphic design have led us to get away from visual pollution, abnormalities, ugliness, and irregularities currently observed in mega cities of our country, and have helped us in accessing into the beautiful and appropriate spaces in the environment of our urban life. In this regard, recognition of and dominance on the concepts of design and environment and their combination are considered to be the matter of crucial importance. The most in-depth definition revealing the need to address environmental graphics is to harmonize the designing of signs, writings, and decorations (whether 2D or 3D) for guiding, informing and any other communication along with creating beauty and establishing a space fitting the Iranian culture and identity to establish order, logic and calm and secure life away from the stresses of mechanical life. Due to the numerous research of artists (the early $20^{\text {th }}$ century) with the aim of promoting the quality and condition of life of civilians and also following the views of artists and thinkers after the modern era in an attempt to exclude art from the enclosed art galleries and generalize art to the daily life and the audience welcome as well, environmental graphics found a special status. Accordingly, the stage for the cooperation of architects and urbanists with painters, sculptors and graphic designers was put and along the increasing development of graphic art in this era, this art used as a branch of visual arts by architects and urbanists. Thus, the art of environmental design with the aid of beautiful and transparent signs provides the opportunity for rapid and easy interaction of man with places as well as events.

\section{REFERENCES}

Sedaghat, N. (2011). Graphic advertising as a new medium in environmental graphics. The development of art education, N. $25^{\text {th }}$, pp. 34-36.

Salavati, M. (2011). The impact of environmental graphics on the urban interactions. Quarterly of motifs, No. $7^{\text {th }}$, pp: $111-134$.

Norouzi, S. The importance of environmental graphics in public places. Tandis, No. 67 $7^{\text {th }}$, pp:18-19. Golkar, K. (2013). Explore the definition of urban design in public places. Tehran: the Center of Iran Architecture and Urbanization Studies and Planning.

Motavali, M. (2015). Investigating and measuring the quality of beauty in the city based on the concept of consecutive views. Journal of Utopia, No. 12th.

Mahmoudi, A. H. (2014). Urban Landscape: A Review of the Theory. Journal of Abadi, No. 53rd, pp: 5461.

Craig. M. Berger, (2005), Way finding, Rotovision SA, Switzerland.

Alasdair Reid (2004). Qutdor's Golden Opportunity: Teddington: Compaign

Betty -Edwards ",Color a course in mastering the art of mixing colors -,"Penguin Publication 2004 Anistatia -Miller \& Jared -Brown logos ",Making a strong mark-"Rockport Publication 2012. 